\title{
Unilateral multicystic dysplastic kidney
}

INSERM

\section{Source}

INSERM. (1999). Orphanet: an online rare disease and orphan drug data base. Unilateral multicystic dysplastic kidney. ORPHA:97363

Unilateral multicystic dysplastic kidney is the form of multicystic dysplastic kidney (MCDK, see this term), a congenital anomaly of the kidney and urinary tract (CAKUT), in which one kidney is large, distended by multiple cysts, and non-functional. 